\title{
Treatment of bisphosphonate-related osteonecrosis using platelet-rich plasma: microtomographic, microscopic, and immunohistochemical analyses
}

\section{Camila Lopes CARDOSO(a) \\ Cláudia CURRA(a) \\ Marcos Martins CURI(b) \\ Mariza Akemi MATSUMOTO(c) \\ Camila Dionísio ARGENTINO(a) (1) \\ Solange de Oliveira Braga \\ FRANZOLIN(d) \\ Dulce CONSTANTINO(d) \\ Daniela Nicolielo BARBOSA(d) \\ Osny FERREIRA JÚNIOR ${ }^{(e)}$}

(a) Universidade do Sagrado Coração,

Department of Oral Surgery, Bauru, SP, Brazil.

(b) Hospital Santa Catarina, Department of

Stomatology, São Paulo, SP, Brazil.

(c) Universidade Estadual Paulista, Department of Histology, Araçatuba, SP, Brazil.

(d) Universidade do Sagrado Coração, Department of Health Sciences, Bauru, SP, Brazil.

(e) Universidade de São Paulo, Department of Oral Surgery, Bauru, SP, Brazil.

Declaration of Interests: The authors certify that they have no commercial or associative interest that represents a conflict of interest in connection with the manuscript.

Corresponding Author:

Camila Lopes Cardoso

E-mail:cardoso_lopes@yahoo.com.br

hitps://doi.org/10.1590/1807-3107bor-2019.vol33.0050

Submitted: 2018, Jul 28

Accepted for publication: November 11, 2018

Last revision: May 22, 2019
Abstract: The present study aimed to investigate the use of plateletrich plasma (PRP) on tooth extraction sites in rats treated with bisphosphonates. Thirty Albinus Wistar male rats were administered $0.035 \mathrm{mg} / \mathrm{kg}$ zoledronic acid intravenously for 8 weeks, divided into four administrations with a 2-week interval between each application, after which their upper right central incisors were extracted to induce the development of bisphosphonate-related osteonecrosis of the jaw (BRONJ). The samples were divided into the following two groups: Group 1 (G1) underwent marginal resection of BRONJ followed by the use of PRP, while Group 2 (G2) underwent resection of BRONJ but without the use of PRP. The treatment groups were evaluated after 14, 28, and 42 days. Clinical, microtomographic, microscopic, and immunohistochemical (IHC) evaluations were performed. Microtomography results revealed no significant difference between the groups $(\mathrm{p}<0.05)$ in any time period. Histomorphometric analysis showed increased bone formation over time for both groups $(p<0.001)$. G1 demonstrated a greater amount of new bone formation than G2 at 28 and 42 days ( $p<0.001$ ), with G1 presenting greater vascularization and a slightly higher VEGF expression. For both groups, RANKL/OPG expression levels were sufficient as a parameter for indicating the rate of bone remodeling in a previously treated area of osteonecrosis groups. Taken together, our findings indicated that the use of PRP improves the resolution process of BRONJ.

Keywords: Disphosphonates; Platelet-Rich Plasma; Wound Healing.

\section{Introduction}

In the literature, strategies on how to manage the treatment of bisphosphonate-related osteonecrosis of the jaw (BRONJ) are still widely debated, and an established protocol with predictable results remains to be established. Considering the failure of the conservative approach, the surgical approach has been widely recommended for handling more advanced cases; however, this entails greater consideration of the bone and symptoms associated with major infections (Stages 2 
and 3) caused by the risk of bacteremia and sepsis in immunocompromised patients, as well as the reduced quality of life. ${ }^{1,2}$

Given this scenario, a variety of surgical treatment options have been used to improve resolution rates of BRONJ cases. Of these therapies, treatment via bone resection combined with the use of growth factors has yielded promising results in the search for a satisfactory cure for this complication. ${ }^{3,4}$ Platelet-rich plasma (PRP) is an autologous source of growth factors that is obtained via centrifugation to yield very high concentrations of human platelets containing various growth factors (derived growth factor, transforming growth factor $\beta$, epidermal growth factor, and vascular endothelial growth factor), which promote the rapid healing of wounds. ${ }^{5}$

Given the absence of well-defined protocols for BRONJ treatment and the scarcity of detailed experimental studies using surgical therapy in combination with PRP, the present study aimed to analyze the surgical therapeutic method proposed by using imaging, microscopic, and immunohistochemical analyses.

\section{Methodology}

The present study was approved by the Ethical Committee on Animal Use (CEUA/USC 12/14) and conducted in accordance with the European Communities Council Directive of 24 November 1986 (86/609/EEC), as well as the Brazilian Society of Laboratory Animal Science (COBEA).

\section{Study design}

Thirty (30) Albinus Wistar male rats, with a mean weight of $180 \mathrm{~g}$, underwent surgical procedures for the extraction of upper right incisors following administration of zoledronic acid (Novartis Pharma Stein AG, Stein, Switzerland). The animals were divided into two groups according to the treatment type. The Experimental group (G1) received autogenous platelet-rich plasma (PRP) following marginal bone resection and curettage of the alveolus, while the Control group (G2) underwent marginal bone resection and curettage of the alveolus without PRP.

\section{Zoledronic acid administration and tooth extraction}

All animals received $0.1 \mathrm{ml}$ of $0.035 \mathrm{mg} / \mathrm{kg} \mathrm{IV}$ zoledronic acid in the tail vein every 15 days for 8 weeks. ${ }^{6}$ For IV administration, the animals were neither sedated nor anesthetized. The administration time was approximately $1 \mathrm{~min}$. No adverse effects were observed during the administrations. After the fourth dose, tooth extractions were performed in accordance with previously described method.,8 At the beginning of the surgical procedures, the animals were sedated by intraperitoneal administration of $1 \%$ ketamine $(0.20 \mathrm{ml} / \mathrm{kg})$ and $2 \%$ xylazine $(0.30 \mathrm{ml} / \mathrm{kg})$ (Francotar, Virbac Ltda., São Paulo, Brazil). Following the surgery, all animals were intramuscularly medicated with 1 $\mathrm{mg} / \mathrm{kg}$ Metamizole sodium per day.

\section{Clinical evaluation}

Considering the chronology of alveolar repair in rats, the sockets were clinically evaluated on day 7 after tooth extraction, and the following diagnostic criteria for BRONJ was considered: presence of bone exposure and/or signs of inflammation and infection, such as suppuration, soft tissue swelling, and the presence of fistulae. ${ }^{9}$ The animals were not anesthetized for this procedure.

\section{Surgical treatment}

The surgical treatment was performed 7 days after the extraction. The 30 animals were divided into two groups. The Experimental group (G1), which was subjected to marginal resection of the region of necrotic bone or to sequestrectomy and socket curettage, followed by insertion of PRP into the viable bone site. The Control group (G2) was subjected to the same treatment, but without PRP. The animals were sedated by intraperitoneal administration of $1 \%$ ketamine $(0.20 \mathrm{ml} / \mathrm{kg})$ and $2 \%$ xylazine $(0.30 \mathrm{ml} / \mathrm{kg})$ (Francotar, Virbac Ltda., São Paulo, Brazil). Platelet-rich plasma was prepared following the standardized protocol reported by Anitua et al. ${ }^{10}$ After anesthesia, $1.0 \mathrm{ml}$ of blood was extracted through an intracardiac puncture using an insulin syringe and a $25 \times 7$ gauge needle. The platelet concentration for each specimen was approximately $0.5 \times 10$ per microliter. Suturing was performed using 
4.0 polyglactin 910 (Vicryl, Johnson and Johnson, São Paulo, Brazil), covering the entire affected region. In the immediate postoperative period, rats in both groups individually received a single $0.1 \mathrm{ml} / \mathrm{kg}$ intramuscular dose of the veterinary antibiotic for prophylaxis of local infection or bacteremia. For analgesia control, a single dose of $0.02-0.5 \mathrm{mg} / \mathrm{kg}$ Buprenorphine was administered subcutaneously and $1 \mathrm{mg} / \mathrm{kg}$ a day of Metamizole sodium for 3 days was administered intramuscularly. After 14, 28, and 42 days, five animals from each group were euthanized; the maxillae were removed and then immersed in $10 \%$ buffered formalin.

\section{MicroCT evaluation}

All specimens were submitted to microCT (CTAn Bruker, SkyScan, Belgium), following the surgical procedure (55Kvp; $72 \mathrm{~mA}$ and high resolution). After axial reconstruction, qualitative analyses and bone histomorphometry were performed using the CTan software (Skyscan, Belgium). A volume of interest ("VOI") was applied on the treated region in equal amounts (in the extension parameters and area of the examination) for all specimens. The volume ratio (VR)/total bone volume (TV), trabeculae number (TN), and trabeculae thickness (TT) were calculated. Each "VOI" had the same geometry and was applied in 200 "slices" of each specimen, selecting the central region of the socket.

\section{Microscopic evaluation}

The specimens were fixed for up to $48 \mathrm{~h}$ before washing in tap water for $24 \mathrm{~h}$. Afterwards, the specimens were demineralized by immersion in $4 \%$ EDTA solution for 20 to 30 days. When demineralization was achieved, the right and left maxillae were separated, and the right side containing the socket was subjected to histotechnical procedures by staining with hematoxylin and eosin (HE). Microscopic analysis was performed considering new bone formation, vascularization, connective tissue and inflammatory infiltrate. Ten fields at 20× magnification of each portion of the socket (apical, middle, and cervical) were captured using a light photomicroscope (Nikon Eclipse 80i trinocular optical microscope, Nikon Instruments,
Inc.), resulting in a total of 30 images per socket per animal. The images were quantitatively analyzed using Image-Pro® Plus version 5.1.2 for Windows XP, (Media Cybernetics, Inc., Rockville, USA.). "GRID" was used for histomorphometry analysis of the variables. The volume density of each structure (bone, connective tissue, blood vessel, and inflammatory infiltrate) was calculated. Subsequently, the mean and standard deviation of the percentages obtained per group were calculated.

\section{Immunohistochemistry}

Immunohistochemical (IHC) analysis was performed to evaluate vascularization and bone remodeling between the two groups. The following primary antibodies were used: VEGF (A-20): sc-152, CD31: Pecam-1 Antibody (M-20); RANK-L and OPG (Santa Cruz Biotechnology ${ }^{\circledR}$, Dallas, USA.). For analysis of the proteins relating to bone formation, maturation, and remodeling, $3-\mu \mathrm{m}$ sections of each specimen were deparaffinized in xylene and rehydrated in a graded series of ethanol to distilled water, immersed in $0.01 \mathrm{M}$ citrate-buffer at $\mathrm{pH}$ 6.0, and subsequently heated in a steamer for $30 \mathrm{~min}$. Histological slices were treated with proteinase $\mathrm{K}$ for $30 \mathrm{~min}$ at room temperature. Endogenous peroxidase was blocked with $2 \%$ hydrogen peroxide for $10 \mathrm{~min}$ and then washed with PBS (phosphate buffer solution). Afterwards, the samples were incubated with the primary polyclonal antibodies anti-RANKL, anti-OPG, anti-VEGF, and anti-CD31 overnight at $4^{\circ} \mathrm{C}$ and then washed thrice for $30 \mathrm{~min}$ each wash. The slices were incubated with biotinylated secondary antibody for $30 \mathrm{~min}$, washed in PBS, and then incubated with streptavidin-peroxidase conjugate (LSAB, Dakocytomation, Carpinteria, USA) for $30 \mathrm{~min}$. The samples were then stained with 3.30-diaminobenzidine tetra-hydrochloride (Sigma Aldrich, St. Louis, USA) and counterstained with Harris hematoxylin. For negative control, incubation with the primary antibody was omitted. Staining signals for each antibody were determined by semi-quantitative analysis, considering the scores ranging from "-" to "+++" (“-": absent, "+": mild, "++": moderate, and "+++": intense) and was performed using two evaluations and a double-blind system..$^{10}$ 


\section{Statistical assessment}

Data obtained from the histomorphometric assessment (microscopic and MicroCT) were organized into a table (Microsoft Office Excel, Redmond, USA) and analyzed using SigmaPlot software (SigmaPlot, San Jose, USA) version 12.3. For each histomorphometric assessment, data were analyzed in relation to the normal distribution using Shapiro-Wilkes and Equal Variance tests, followed by 2-way ANOVA (Group and Period) and the Tukey test to detect differences between the groups (SigmaPlot 12.0, San Jose, USA). $p<0.05$ was considered statistically significant.

\section{Results}

\section{Gross examination}

Seven days after extraction, 12 out of 30 animals showed bone exposure, with five animals presenting suppuration and two animals with bone sequestration.

\section{MicroCT evaluation}

Based on microtomographic examination, all specimens showed areas of osteolysis and fracture or loss of socket integrity in some regions of the bone adjacent to the socket. When the new bone formation within the socket is considered, qualitative analysis revealed an increase in new bone formation over time which is expected in the process of alveolar repair of a healthy socket. At 42 days, increased new bone formation was observed compared to days 28 and 14 (Figure 1). Considering the results of the histomorphometric analysis, no significant difference was found between the groups $(p<0.05)$ (Table 1$)$.

\section{Histological analysis}

\section{Group 1 (with PRP)}

On day 14 , discrete bone formation $(\mathrm{BF})$ was more abundant on the walls and the apical third of the socket than in the central areas. Bone trabeculae were
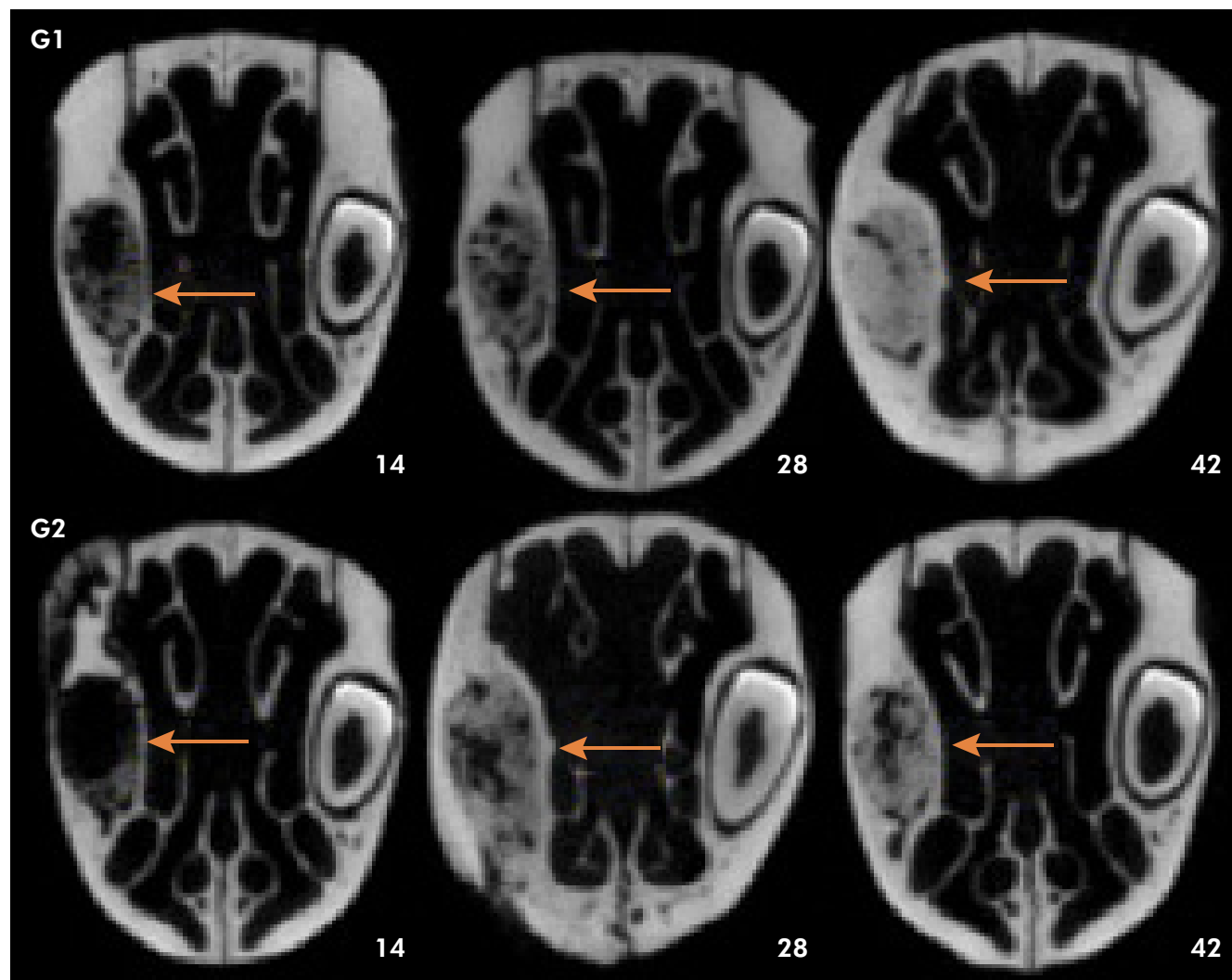

Figure 1. Photomicrographs of group $1(G 1)$, treated with PRP, and group 2 (G2), without PRP, showing bone neoformation within the alveolus (arrow) on days 14, 28, and 42. 
Table 1. Results of statistical tests, histomorphometric analysis between groups, periods and analyzes.

\begin{tabular}{|c|c|c|}
\hline Evaluation & $\mathrm{p}$ - value & Statistic test \\
\hline \multicolumn{3}{|l|}{ G1 } \\
\hline \multicolumn{3}{|c|}{14 days $\times 28$ days $\times 42$ days } \\
\hline VO/NT(\%) & $0,001896^{*}$ & ANOVA \\
\hline ET & $0,0009345^{*}$ & ANOVA \\
\hline NT & $0,01854^{*}$ & ANOVA \\
\hline \multicolumn{3}{|l|}{ G2 } \\
\hline \multicolumn{3}{|c|}{14 dias $\times 42$ dias } \\
\hline VONT(\%) & 0,2159 & Mann-Whitney \\
\hline ET & 0,20097 & t Student \\
\hline NT & 0,11812 & t Student \\
\hline \multicolumn{3}{|l|}{ G1 x G2 } \\
\hline \multicolumn{3}{|l|}{ VONT(\%) } \\
\hline 14 days & 0,8852 & Mann-Whitney \\
\hline 28 days & - & - \\
\hline 42 days & 0,8597 & Mann-Whitney \\
\hline \multicolumn{3}{|l|}{ ET } \\
\hline 14 days & 0,42937 & t Student \\
\hline 28 days & - & - \\
\hline 42 days & 0,12959 & t Student \\
\hline \multicolumn{3}{|l|}{ NT } \\
\hline 14 days & 0,12959 & t Student \\
\hline 28 days & - & - \\
\hline 42 days & 0,34559 & t Student \\
\hline
\end{tabular}

*statistically significant difference.

observed to be surrounded by a highly vascularized connective tissue. The presence of blood vessels was observed across the whole socket, and was particularly conspicuous in the middle and cervical thirds. Discrete mononuclear inflammatory infiltrate was observed. Greater formation of new bone was observed on day 28. The presence of blood vessels was observed in the entire socket, notably in the middle (M) and apical (A) thirds (Figure 2). Discrete inflammatory mononuclear infiltrate was observed. On day 42 , bone remodeling was noted, marked by basophilic reversal lines. Blood vessels were present in all socket thirds (Figure 2).

\section{Group 2}

On day 14, discrete (BF) was more abundantly observed on the walls and the apical third of socket than the central areas. Bone trabeculae were distributed throughout the socket and were highly vascularized. Discrete inflammatory mononuclear infiltrate was observed, along with mild polymorphonuclear infiltrate represented by neutrophils in the cervical third. On day 28, discrete newly formed bone tissue was observed in the cervical third, with the presence of granulation tissue in some specimens. On day 42, greater new bone formation was observed, except in the cervical third. The connective tissue found in the bone trabeculae was mature, with the presence of discrete mononuclear inflammatory infiltrate. Blood vessels were primarily observed in the apical and cervical thirds (Figure 2).

Based on histomorphometric analysis, both groups showed increased new bone formation over time $(p<0.001)$. G1 showed more pronounced new bone formation than G2 on days 28 and 42 ( $p<0.001$ ). In G1, the middle and cervical thirds of the socket revealed increased new bone formation than in G2 ( $p<0.001)$. On days 28 and 42, G2 showed more connective tissue than G1 ( $p<0.001)$. We observed no statistically significant difference in inflammatory infiltrate between the groups. G1 presented greater blood vessels than G2 in all time periods ( $p<0.001)$.

\section{Immunohistochemistry evaluation}

\section{VEGF - Group 1}

On days 14 and 28 days, immunolabeling ranged from mild to moderate for the anti-VEGF antibody, especially in connective tissue fibroblast cells, mononuclear leukocytes, and focal regions of the bone tissue. On day 42, discrete immunolabeling was observed in the bone tissue, especially in osteocytes.

\section{VEGF - Group 2}

Immunolabeling was also detected on days 14 , 28 , and 42 , especially in the connective tissue and osteocytes, but was less pronounced than that in G1 (Figure 3).

\section{CD31 - Group 1}

Absent to mild immunolabeling was observed at all time intervals. When present at 14 days, discrete 


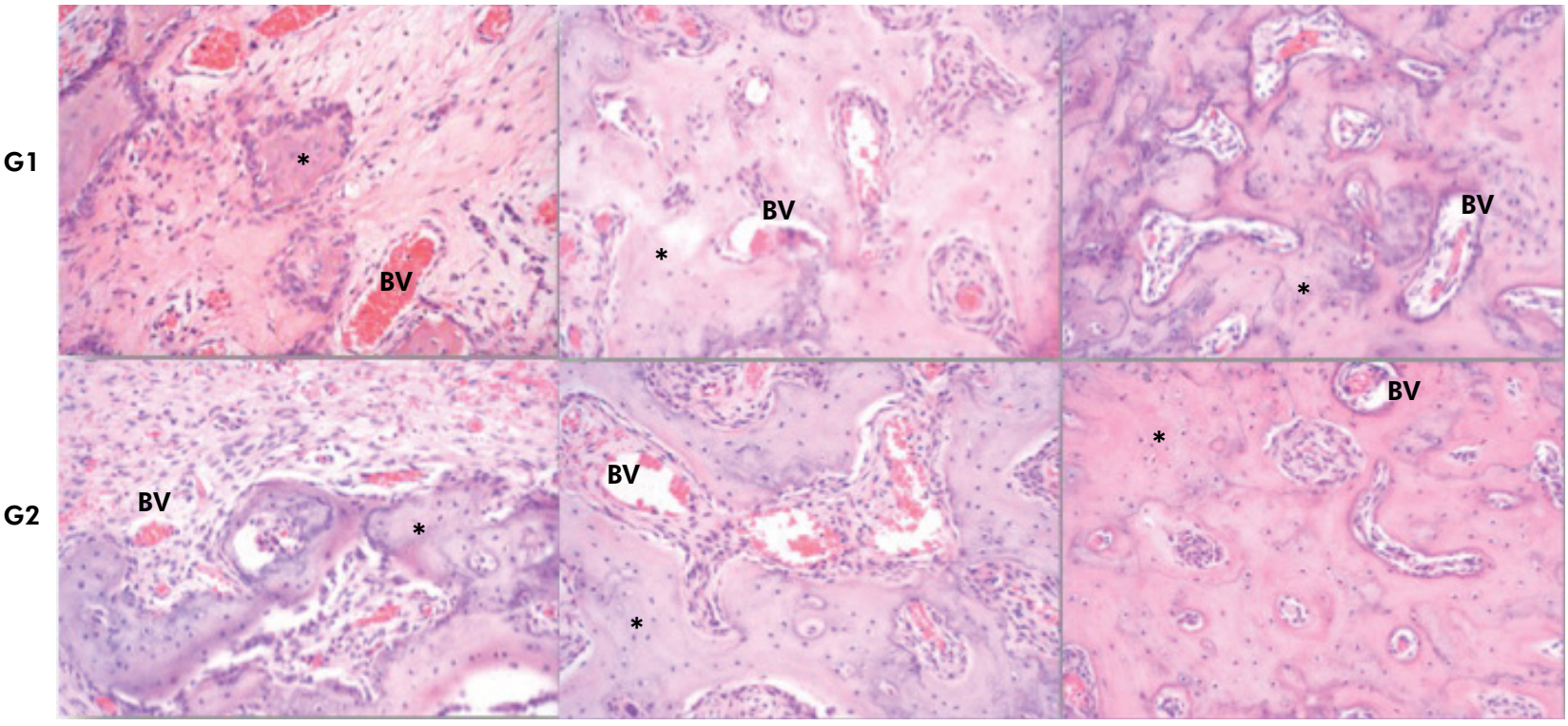

Figure 2. Photomicrographs of group $1(G 1)$, treated with PRP, and group $2(G 2)$, without PRP, showing blood vessels (BV) in neoformed bone trabeculae $\left(^{*}\right)$ on days 14,28 , and 42 .

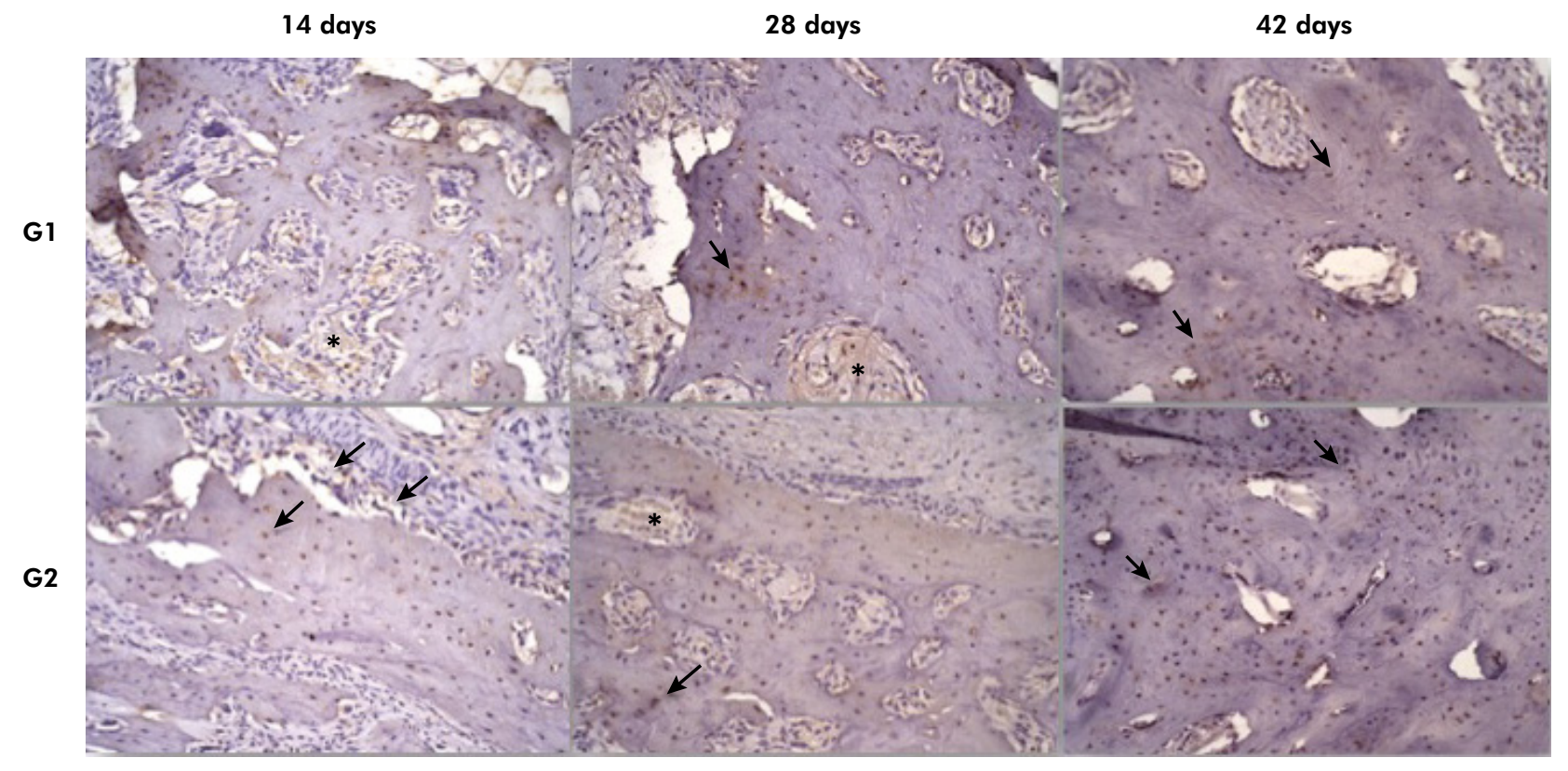

Figure 3. Photomicrographs of group 1 (G1), treated with PRP, and group 2 (G2), without PRP, showing the immunostaining results for the anti-VEGF antibody in osteocytes and osteoblasts (arrows) and connective tissue $\left(^{*}\right.$ ) on days 14, 28, and 42 (Magnification $=200 \times$ ).

immunolabeling was observed in the connective tissue, especially in inflammatory cells, which were predominantly mononuclear. On days 28 and 42 , discrete immunolabeling was observed in the endothelial cells of the blood vessels.

\section{CD31 - Group 2}

Similar to Group 1, absent to mild immunolabeling was present all time intervals in the same structures. On days 28 and 42, few specimens were positive for the CD31 antibody (Figure 4). 


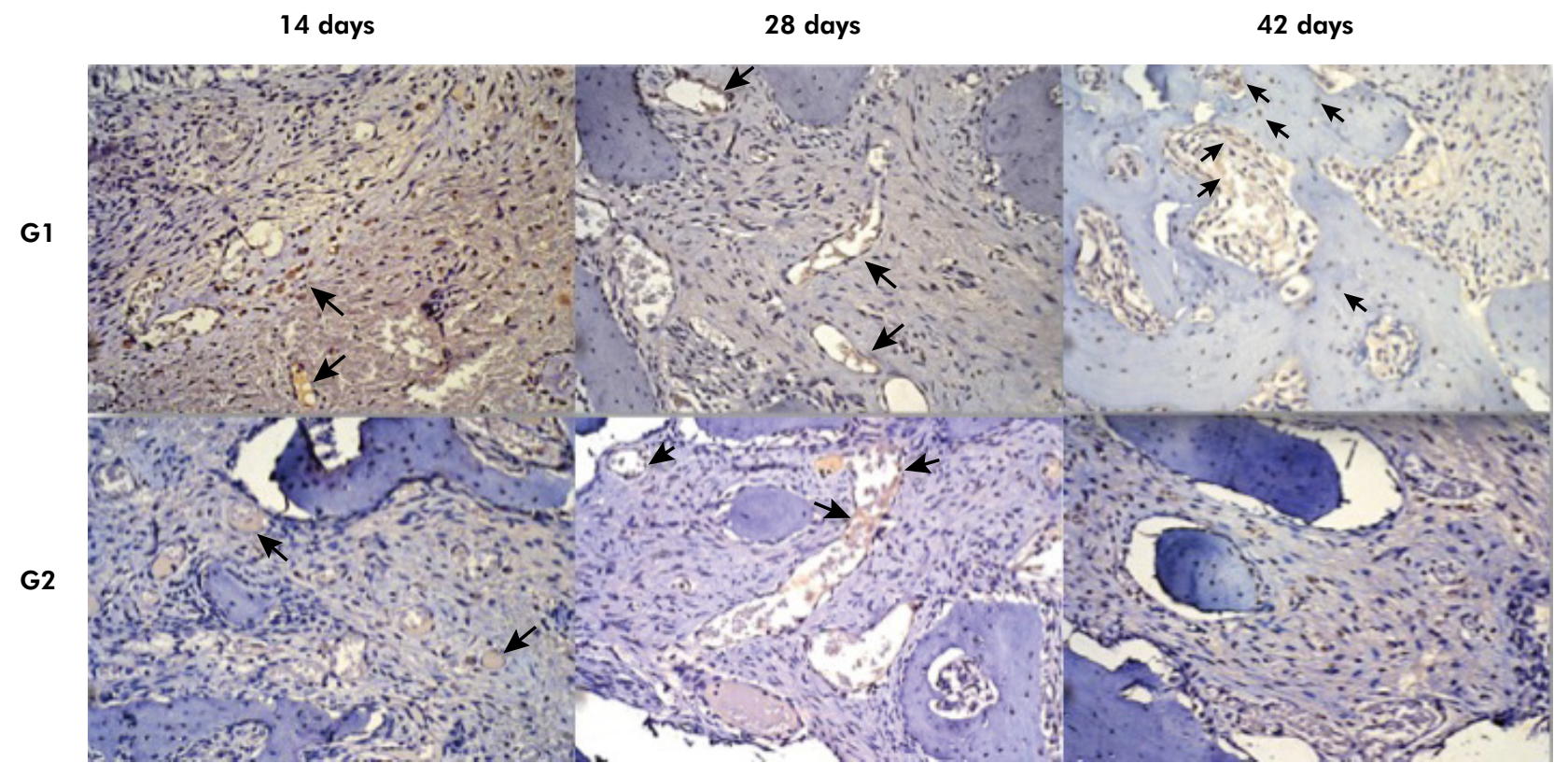

Figure 4. Photomicrographs of group $1(G 1)$, treated with PRP, and group 2 (G2), without PRP, showing the absence of signals corresponding to the anti-CD31 antibody on days 14, 28, and 42. Detailed in endothelial cells and mononuclear inflammatory cells (arrows) (Magnification $=200 \times$ ).

\section{RANK-L - Group 1}

On day 14, intense immunolabeling was observed in the connective tissue, especially in the stromal cells (fibroblasts and osteoblasts). In addition, moderate immunolabeling was observed in the bone tissue. On day 28 , mild-to-moderate immunolabeling was observed in the connective tissue, and moderate immunolabeling was observed in the bone tissue (osteocytes). On day 42, moderate immunolabeling was observed in the osteocytes, and mild immunolabeling was observed in the connective tissue.

\section{RANK-L - Group 2}

On day 14, moderate-to-intense immunolabeling was observed in the connective tissue, especially in the stromal cells (fibroblasts and osteoblasts). In addition, moderate immunolabeling was detected in the bone tissue. On day 28 , mild-to-moderate immunolabeling was observed in the connective tissue, and moderate immunolabeling was observed in the bone tissue (osteocytes). On day 42, moderate immunolabeling was observed in the osteocytes (Figure 5).

\section{OPG - Group 1}

On day 14, mild immunolabeling was observed in the connective tissue, and moderate immunolabeling was observed in the osteocytes. On day 28, mild to moderate immunolabeling was detected in the bone tissue, while moderate immunolabeling was observed in the stromal cells. On day 42, absent to mild immunolabeling was observed in the connective tissue and, when present, in osteocytes of bone tissue.

\section{OPG - Group 2}

On day 14, mild immunolabeling was observed in both bone tissue (osteocytes) and connective tissue. On day 28 , mild immunolabeling was observed in the bone tissue, and on day 42 , moderate immunolabeling was present in the bone tissue and connective tissue (Figure 6). The results of semiquantitative analysis are shown in Table 2.

\section{Discussion}

In the literature, the therapeutic treatment of BRONJ remains controversial, considering the absence of a definitive protocol with good predictability. 
- Treatment of bisphosphonate-related osteonecrosis using platelet-rich plasma: microtomographic, microscopic, and immunohistochemical analyses

14 days 28 days 42 days

G1

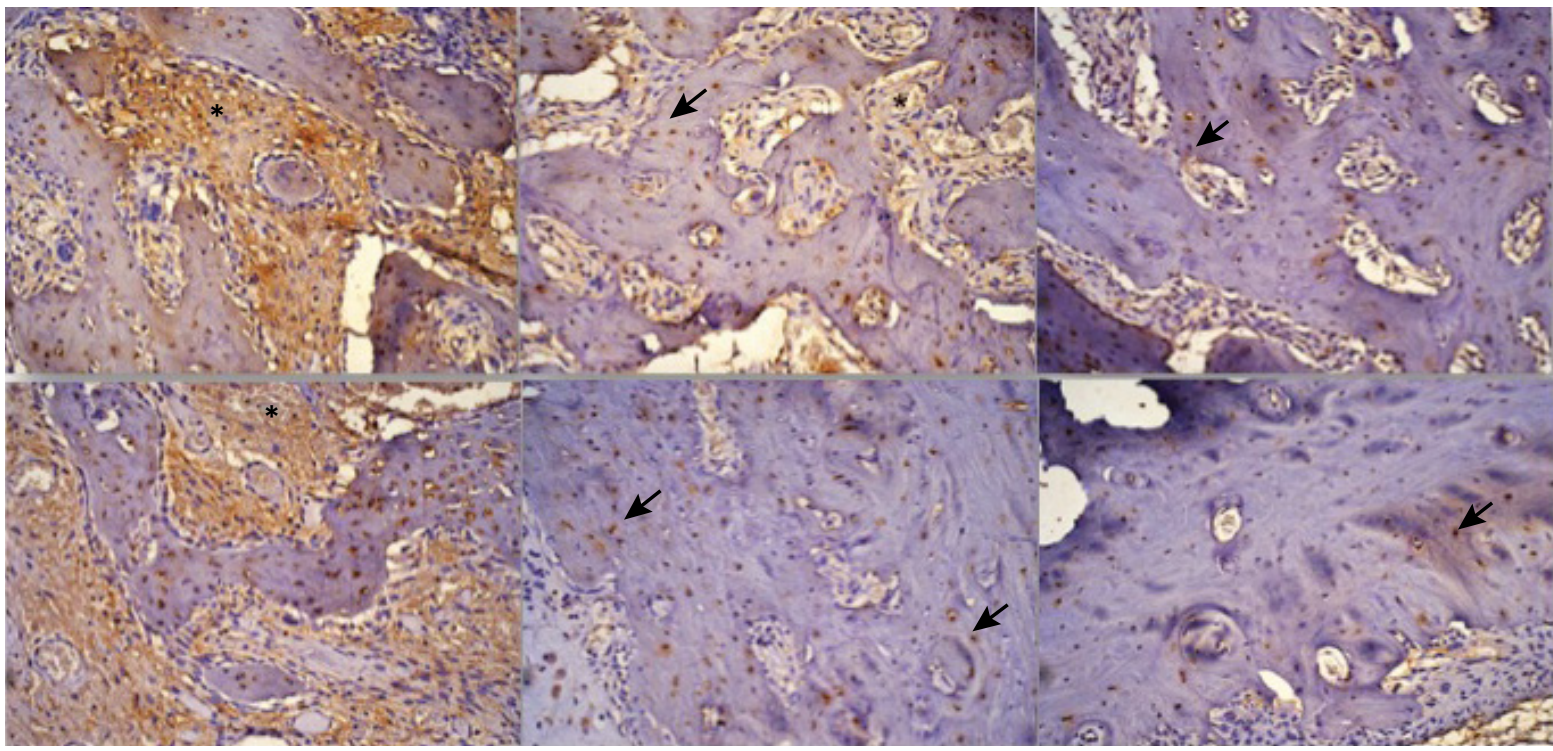

Figure 5. Photomicrographs of group $1(G 1)$, treated with PRP, and group 2 (G2), without PRP, demonstrates immunostaining for the anti-RANKL antibody at 14, 28 and 42 days, respectively. Detailed view of connective tissue and osteocytes marked by arrows. (Magnification $=200 \times)$.

14 days 28 days $\quad 42$ days

G1

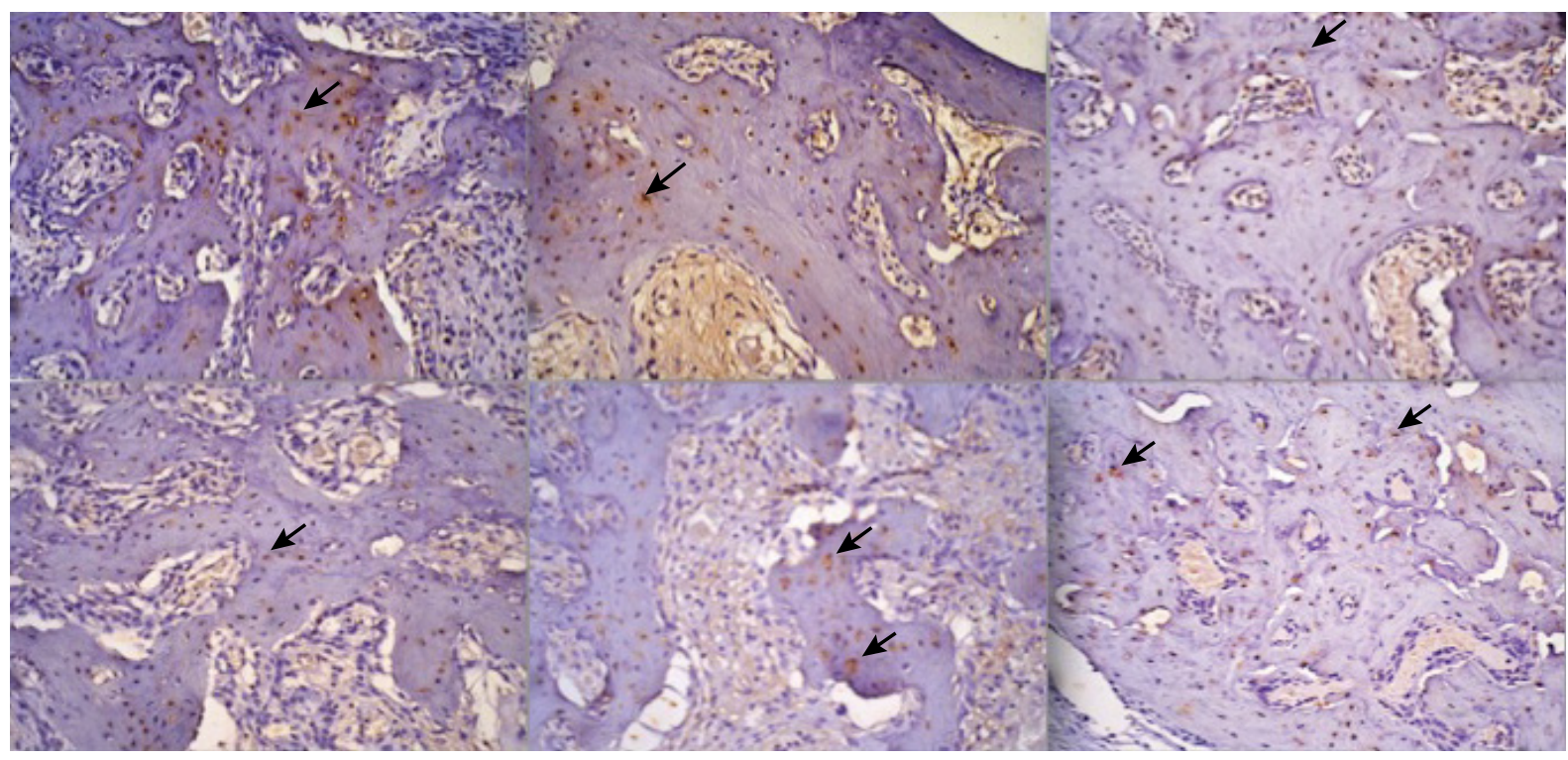

Figure 6. Photomicrographs of group $1(G 1)$, treated with PRP, and group 2 (G2), without PRP, showing the immunostaining results for the anti-OPG antibody on days 14, 28, and 42. Detailed view of osteocytes marked by arrows. (Magnification $=200 \times$ ).

The first studies conducted to evaluate the surgical approaches for the treatment of BRONJ were published in $2006^{12}$. Since then, various other studies reported findings on the therapeutic treatment of BRONJ, with the aim of identifying the optimal surgical approach. $13,14,15,16,17,18,19,20,21,22$ The current consensus for BRONJ treatment, as recommended by the AAOMS ${ }^{2}$, dictates that the treatment strategies should always 
Table 2. Frequency of results in semiquantitative analysis of each specimen. Absent immunolabeling (-); slight $(+)$; moderate $(++)$ and intense $(+++)$.

\begin{tabular}{|c|c|c|c|c|c|}
\hline Sample/Group & Days & VEGF & CD31 & OPG & RANKL \\
\hline $1 / G 1$ & 14 & ++ & - & + & ++ \\
\hline 2/G1 & 14 & + & - & + & ++ \\
\hline 3/G1 & 14 & ++ & + & + & +++ \\
\hline $4 / G 1$ & 14 & ++ & - & + & ++ \\
\hline 5/G1 & 14 & + & + & ++ & ++ \\
\hline 6/G1 & 28 & ++ & - & + & + \\
\hline $7 / G 1$ & 28 & + & + & ++ & + \\
\hline 8/G1 & 28 & + & + & ++ & ++ \\
\hline 9/G1 & 28 & ++ & - & + & ++ \\
\hline 10/G1 & 28 & ++ & - & + & + \\
\hline $11 / G 1$ & 42 & + & + & ++ & ++ \\
\hline 12/G1 & 42 & ++ & - & + & ++ \\
\hline 13/G1 & 42 & + & - & + & ++ \\
\hline $14 / G 1$ & 42 & + & - & + & ++ \\
\hline $15 / G 1$ & 42 & + & - & + & + \\
\hline 16/G2 & 14 & + & + & + & + \\
\hline $17 / G 2$ & 14 & ++ & - & + & ++ \\
\hline 18/G2 & 14 & + & + & + & ++ \\
\hline 19/G2 & 14 & + & - & + & ++ \\
\hline 20/G2 & 14 & + & - & ++ & +++ \\
\hline $21 / G 2$ & 28 & + & - & + & ++ \\
\hline $22 / G 2$ & 28 & + & + & + & + \\
\hline $23 / G 2$ & 28 & + & - & + & + \\
\hline 24/G2 & 28 & + & - & + & ++ \\
\hline $25 / G 2$ & 28 & + & + & + & ++ \\
\hline $26 / G 2$ & 42 & + & + & + & ++ \\
\hline $27 / G 2$ & 42 & + & + & ++ & ++ \\
\hline 28/G2 & 42 & + & - & + & + \\
\hline $29 / G 2$ & 42 & + & - & + & ++ \\
\hline 30/G2 & 42 & + & - & + & ++ \\
\hline
\end{tabular}

be in accordance with the stage of the BRONJ disease. The healthcare provider should initially consider the most conservative approach and, when necessary, carry out surgical intervention when infections and comorbidities are present to effectively improve the patient's quality of life.
Recent systematic review studies have exposed the dearth of scientific evidence discussing the treatment of BRONJ, making it difficult to draw conclusions on this topic. ${ }^{23}$ A recent study reviewed the following types of surgical approaches for BRONJ treatment: debridement or sequestrectomy and surgical resection and, in some cases, reconstruction of the affected areas. Clinical success was observed in the majority of cases who received surgical treatment; however, in addition to the lack of detail in the cases presented, the patient outcomes during the follow-up period varied greatly. ${ }^{24}$

The difficulty in identifying effective treatments for osteonecrosis explains the emergence of adjuvant therapy or the use of growth factors combined with resections in an attempt to increase the success rates of the surgical approach for this disorder. Regarding the surgical treatment proposed in this study, the use of platelet-rich plasma (PRP) in clinical settings has been reported since 2007.,25,26,27,28,29 The utilization of PRP aims to improve the healing process, given the existence of multiple growth factors that promote tissue vascularization and amidst the lack of vascularization in the pathogenesis of osteonecrosis. ${ }^{2}$ The use of PRP was first described in 2007; in particular, PRP treatment followed by marginal bone resection in the surgical site of three clinical cases of BRONJ were unresponsive to conservative treatment. ${ }^{13}$ All the cases would later be completely resolved.Subsequently, other studies reported using the same surgical procedures, also with satisfactory results. ${ }^{26,29}$

Another study demonstrated clinical experiences with the use of marginal bone resection and PRP in the surgical treatment of 25 patients suffering from BRONJ. ${ }^{1}$ Eighty percent $(80 \%)$ of the patients recovered, presenting full and complete healing of the oral mucosa and with no signs of exposed bone, as observed during the follow-up period. The authors concluded that bone resection combined with PRP was effective for the majority of patients in the advanced stages of BRONJ. Another clinical study evaluating the application of PRP reported a $100 \%$ success rate. ${ }^{28}$

A literature review evaluated the surgical treatment of 72 patients with BRONJ, out of which 
15 patients received surgical treatment without PRP and 34 patients with PRP. ${ }^{26}$ A comparison of the two groups showed that the success rate of surgery without PRP was lower compared to the group with PRP. Another systematic review comprising 18 studies ${ }^{16}$ concluded that PRP could significantly improve the resolution of BRONJ. Clinical cure was observed in $91.6 \%$ of the 143 patients treated. However, the authors advise caution in the interpretation of the results, given the low degree of evidence in the studies and the small sample sizes. Moreover, the studies presented a number of limitations because of differences in the study focus and methodologies, specifically in terms of the type of bisphosphonates, clinical indication, treatment duration, trigger factors, type of study, length of follow-up, details of the PRP preparation, and the evaluation of the treatment success.

We found little histomorphometric evidence of repair in these studies when comparing areas of patients with BRONJ who were treated with PRP. The present study aimed to evaluate the effect of PRP on alveolar repair in terms of the microscopic, imaging, and immunohistochemical aspects. Given the limitations of a clinical study, the experimental model applied in this investigation was found to be adequate for the proposed analysis. As in previous studies, ${ }^{11,30}$ the model of osteonecrosis induced by zoledronic acid was shown to be effective, considering that all the samples presented significant bone changes under computed microtomography. In this context, we retrieved only one experimental study on animals, which conducted microscopic evaluation of the effects of PRP in the treatment of BRONJ, wherein rats subjected to this therapy with zoledronic acid and received PRP presented better bone repair compared to the rats in the treatment group that did not receive PRP. ${ }^{31}$

Considering the results of the histomorphometric analysis in the computed microtomography examination, slightly greater new bone formation was observed in the group receiving PRP. Given that the computed microtomography examination only evaluated the bone structures, it can therefore be safely concluded that microscopic examination was fundamental to a detailed investigation of the repair process. Optical microscope examination revealed in greater detail significant new bone formation compared to the group without PRP. Importantly, these significant results were recorded on days 28 and 42, which are the most pertinent time periods for evaluating new bone formation.

The expression of anti-VEGF in bone tissue reflects the activity of the osteoblast cells in the induction of revascularization in repaired areas. ${ }^{32}$ Osteocytes also produce VEGF, particularly when it is necessary to supply apoptotic osteocytes and during bone remodeling. ${ }^{33}$ In this study, an analysis of the reaction of the samples of anti-CD31 antibody revealed a variation from absent-to-slight labeling and a notable nonspecific labeling. In addition, we observed no significant difference between the treated groups, such that we did not consider it appropriate to draw conclusions thereon. In the light of the results, the histomorphometric analysis can be considered an important approach for reliably comparing the two groups.

The use of PRP in the present study likely improved vascularization, as evidenced by histomorphometry results, which revealed more abundant blood vessels in the group that received PRP. In addition, the PRP group showed stronger immunolabeling signals for the anti-VEGF antibodies. We considered the results relating to vascularization significant enough to draw a conclusion, since vascularization is a crucial factor affecting the prognosis of BRONJ. The observed results are most likely caused by the presence of PRP in the surgical site based on prior evidence involving the use of PRP.

Qualitative evaluation revealed that bone remodeling activity was delimited by lines of reversal in both groups. The rate of bone remodeling was found to be normal within immunohistochemical parameters, as demonstrated by the equilibrium in the RANKL:OPG ratio of expression levels. Although the osteoclasts have not been quantitatively analyzed in this study, the analysis of the RANKL:OPG expression ratio was sufficient for determining the rate of bone remodeling in a previously treated area of osteonecrosis. 


\section{Conclusions}

In the present study, the experimental group (G1) that received treatment with PRP presented improved bone repair compared to the control group (G2). The analysis took into account new bone formation and vascularization, which were both quantitatively evaluated.

\section{Acknowledgments}

Thanks are due to São Paulo Research Foundation (FAPESP - 2014/10693-6). The authors are grateful to Maira Cristina Rondina Couto from Sagrado Coração University, for histology and immunohistochemistry assistance and to the Endodontics Department, Universidade de São Paulo (FOB/USP), for the use of MicroCT.

\section{References}

1. Curi MM, Cossolin GS, Koga DH, Zardetto C, Christianini S, Feher O, et al. Bisphosphonate-related osteonecrosis of the jaws: an initial case series report of treatment combining partial bone resection and autologous platelet-rich plasma. J Oral Maxillofac Surg. 2011 Sep;69(9):2465-72. https://doi.org/10.1016/i.joms.2011.02.078

2. Ruggiero SL, Dodson TB, Fantasia J, Goodday R, Aghaloo T, Mehrotra B, et al. American Association of Oral and Maxillofacial Surgeons position paper on medication-related osteonecrosis of the jaw-2014 update. J Oral Maxillofac Surg. 2014 Oct;72(10):1938-56. https://doi.org/10.1016/i.joms.2014.04.031

3. Marx RE. Platelet-rich plasma: evidence to support its use. J Oral Maxillofac Surg. 2004 Apr;62(4):489-96. https://doi.org/10.1016/i.joms.2003.12.003

4. Plachokova AS, Nikolidakis D, Mulder J, Jansen JA, Creugers NH. Effect of platelet-rich plasma on bone regeneration in dentistry: a systematic review. Clin Oral Implants Res. 2008 Jun;19(6):539-45. https://doi.org/10.1111/j.1600-0501.2008.01525.x

5. Dugrillon A, Eichler H, Kern S, Klüter H. Autologous concentrated platelet-rich plasma (cPRP) for local application in bone regeneration. Int J Oral Maxillofac Surg. 2002 Dec;31(6):615-9. https://doi.org/10.1054/ijom.2002.0322

6. Hokugo A, Christensen R, Chung EM, Sung EC, Felsenfeld AL, Sayre JW, et al. Increased prevalence of bisphosphonate-related osteonecrosis of the jaw with vitamin D deficiency in rats. J Bone Miner Res. 2010 Jun;25(6):1337-49. https://doi.org/10.1002/jbmr.23

7. Cardoso CL, Ferreira Júnior O, Carvalho PS, Dionísio TJ, Cestari TM, Garlet GP. Experimental dry socket: microscopic and molecular evaluation of two treatment modalities. Acta Cir Bras. 2011 Oct;26(5):365-72. https://doi.org/10.1590/S0102-86502011000500007

8. Matsumoto MA, Furquim EMA, Gonçalves A, Santiago-Júnior JF, Saraiva PP, Cardoso CL, et al. Aged rats under zoledronic acid therapy and oral surgery. J Craniomaxillofac Surg. 2017 May;45(5):781-7. https://doi.org/10.1016/i.jcms.2017.02.002

9. Vilarinho JL, Ferrare N, Moreira AM, Moura HF, Acevedo AC, Chaves SB, et al. Early bony changes associated with bisphosphonate-related osteonecrosis of the jaws in rats: A longitudinal in vivo study. Arch Oral Biol. 2017 Oct;82:79-85 https://doi.org/10.1016/i.archoralbio.2017.06.002

10. Anitua E, Sánchez M, Nurden AT, Nurden P, Orive G, Andía I. New insights into and novel applications for platelet-rich fibrin therapies. Trends Biotechnol. 2006 May;24(5):227-34. https://doi.org/10.1016/i.tibtech.2006.02.010

11. Luvizuto ER, Dias SM, Queiroz TP, Okamoto T, Garcia IR Jr, Okamoto R, et al. Osteocalcin immunolabeling during the alveolar healing process in ovariectomized rats treated with estrogen or raloxifene. Bone. 2010 Apr;46(4):1021-9. https://doi.org/10.1016/i.bone.2009.12.016

12. Ruggiero SL, Fantasia J, Carlson E. Bisphosphonate-related osteonecrosis of the jaw: background and guidelines for diagnosis, staging and management. Oral Surg Oral Med Oral Pathol Oral Radiol Endod. 2006 Oct;102(4):433-41. https://doi.org/10.1016/i.tripleo.2006.06.004

13. Bedogni A, Saia G, Bettini G, Tronchet A, Totola A, Bedogni G, et al. Long-term outcomes of surgical resection of the jaws in cancer patients with bisphosphonate-related osteonecrosis. Oral Oncol. 2011 May;47(5):420-4. https://doi.org/10.1016/i.oraloncology.2011.02.024 PMID:21439892

14. Curi MM, Cossolin GS, Koga DH, Araújo SR, Feher O, Santos MO, et al. Treatment of avascular osteonecrosis of the mandible in cancer patients with a history of bisphosphonate therapy by combining bone resection and autologous platelet-rich plasma: report of 3 cases. J Oral Maxillofac Surg. 2007 Feb;65(2):349-55. https://doi.org/10.1016/i.joms.2005.12.051

15. Carlson ER. Management of antiresorptive osteonecrosis of the jaws with primary surgical resection. J Oral Maxillofac Surg. 2014 Apr;72(4):655-7. https://doi.org/10.1016/i.joms.2013.12.007

16. Del Fabbro M, Gallesio G, Mozzati M. Autologous platelet concentrates for bisphosphonate-related osteonecrosis of the jaw treatment and prevention. A systematic review of the literature. Eur J Cancer. 2015 Jan;51(1):62-74. https://doi.org/10.1016/j.ejca.2014.10.015 
Treatment of bisphosphonate-related osteonecrosis using platelet-rich plasma: microtomographic, microscopic, and immunohistochemical analyses

17. Eckardt AM, Lemound J, Lindhorst D, Rana M, Gellrich NC. Surgical management of bisphosphonate-related osteonecrosis of the jaw in oncologic patients: a challenging problem. Anticancer Res. 2011 Jun;31(6):2313-8.

18. Graziani F, Vescovi P, Campisi G, Favia G, Gabriele M, Gaeta GM, et al. Resective surgical approach shows a high performance in the management of advanced cases of bisphosphonate-related osteonecrosis of the jaws: a retrospective survey of 347 cases. J Oral Maxillofac Surg. 2012 Nov;70(11):2501-7. https://doi.org/10.1016/i.joms.2012.05.019

19. Scoletta M, Arduino PG, Dalmasso P, Broccoletti R, Mozzati M. Treatment outcomes in patients with bisphosphonate-related osteonecrosis of the jaws: a prospective study. Oral Surg Oral Med Oral Pathol Oral Radiol Endod. 2010 Jul;110(1):46-53. https://doi.org/10.1016/j.tripleo.2010.02.020PMID:20452252

20. Wilde F, Heufelder M, Winter K, Hendricks J, Frerich B, Schramm A, et al. The role of surgical therapy in the management of intravenous bisphosphonates-related osteonecrosis of the jaw. Oral Surg Oral Med Oral Pathol Oral Radiol Endod. 2011 Feb;111(2):153-63. https://doi.org/10.1016/i.tripleo.2010.04.015

21. Stockmann P, Burger M, Wilmowsky C, Ebker T, Lutz R, Baversachs A, et al. The outcome after surgical therapy of bisphosphonateassociated osteonecrosis of the jaw_results of a clinical case series with an average follow-up of 20 months. Clin Oral Investig. 2014 May;18(4):1299-304.

22. Franco S, Miccoli S, Limongelli L, Tempesta A, Favia G, Maiorano E, et al. New dimensional staging of bisphosphonate-related osteonecrosis of the jaw allowing a guided surgical treatment protocol: long-term follow-up of 266 lesions in neoplastic and osteoporotic patients from the university of bari. Int J Dent. 2014;2014:935657. https://doi.org/10.1155/2014/935657

23. Rollason V, Laverrière A, MacDonald LC, Walsh T, Tramèr MR, Vogt-Ferrier NB. Interventions for treating bisphosphonate-related osteonecrosis of the jaw (BRONJ). Cochrane Database Syst Rev. 2016 Feb;2:CD008455. https://doi.org/10.1002/14651858.CD008455.pub2

24. Silva LF, Curra C, Munerato MS, Deantoni CC, Matsumoto MA, Cardoso CL, et al. Surgical management of bisphosphonate-related osteonecrosis of the jaws: literature review. Oral Maxillofac Surg. 2016 Mar;20(1):9-17. https://doi.org/10.1007/s10006-015-0538-x

25. Lee CY, David T, Nishime M. Use of platelet-rich plasma in the management of oral biphosphonate-associated osteonecrosis of the jaw: a report of 2 cases. J Oral Implantol. 2007;33(6):371-82. https://doi.org/10.1563/1548-1336(2007)33[371:UOPPIT]2.0.CO;2

26. Longo F, Guida A, Aversa C, Pavone E, Di Costanzo G, Ramaglia L, et al. Platelet rich plasma in the treatment of bisphosphonaterelated osteonecrosis of the jaw: personal experience and review of the literature. Int J Dent. 2014;2014:298945. https://doi.org/10.1155/2014/298945

27. Mozzati M, Gallesio G, Arata V, Pol R, Scoletta M. Platelet-rich therapies in the treatment of intravenous bisphosphonate-related osteonecrosis of the jaw: a report of 32 cases. Oral Oncol. 2012 May;48(5):469-74. https://doi.org/10.1016/i.oraloncology.2011.12.004

28. Bocanegra-Pérez S, Vicente-Barrero M, Knezevic M, Castellano-Navarro JM, Rodríguez-Bocanegra E, Rodríguez-Millares J, et al. Use of platelet-rich plasma in the treatment of bisphosphonate-related osteonecrosis of the jaw. Int J Oral Maxillofac Surg. 2012 Nov;41(11):1410-5. https://doi.org/10.1016/i.ijom.2012.04.020

29. Adornato MC, Morcos I, Rozanski J. The treatment of bisphosphonate-associated osteonecrosis of the jaws with bone resection and autologous platelet-derived growth factors. J Am Dent Assoc. 2007 Jul;138(7):971-7. https://doi.org/10.14219/jada.archive.2007.0294

30. Curra C, Cardoso CL, Ferreira O, Curi MM, Matsumoto MA, Cavenago BC, et al. Medication-related osteonecrosis of the jaw. Introduction of a new modified experimental model. Acta Cir Bras. 2016 May;31(5):308-13. https://doi.org/10.1590/S0102-865020160050000003

31. Sarkarat F, Kalantar Motamedi MH, Jahanbani J, Sepehri D, Kahali R, Nematollahi Z. Platelet-Rich Plasma in treatment of zolendronic acid-induced bisphosphonate-related osteonecrosis of the jaws. Trauma Mon. 2014 Apr;19(2):e17196. https://doi.org/10.5812/traumamon.17196

32. Zuscik MJ. Skeletal Healing. In: Favus M, ed. Primer on the metabolic bone diseasees and disorders of mineral metabolismo. 8th ed. Washinton, DC: American Society for Bone and Mineral Rsearch; 2013. p.90-98.. https://doi.org/10.1002/9781118453926.ch11 33. Jilka RL, Noble B, Weinstein RS. Osteocyte apoptosis. Bone. 2013 Jun;54(2):264-71. https://doi.org/10.1016/i.bone.2012.11.038 